\title{
Measuring the quality of patient-centered care: why patient-reported measures are critical to reliable assessment
}

This article was published in the following Dove Press journal:

Patient Preference and Adherence

24 June 2015

Number of times this article has been viewed

\author{
Flora Tzelepis \\ Robert W Sanson-Fisher \\ Alison C Zucca \\ Elizabeth A Fradgley \\ Priority Research Centre for Health \\ Behaviour, University of Newcastle \\ and Hunter Medical Research \\ Institute, Newcastle, NSW, Australia
}

Correspondence: Flora Tzelepis Priority Research Centre for Health Behaviour, University of Newcastle, University Drive, Callaghan, NSW 2308, Australia

Tel +6I 249246275

Fax +6I 249246490

Email flora.tzelepis@newcastle.edu.au
Purpose: The Institute of Medicine (IOM) identified patient-centeredness as crucial to quality health care. The IOM endorsed six patient-centeredness dimensions that stipulated that care must be: respectful to patients' values, preferences, and expressed needs; coordinated and integrated; provide information, communication, and education; ensure physical comfort; provide emotional support; and involve family and friends. Patient-reported measures examine the patient's perspective and are essential to the accurate assessment of patient-centered care. This article's objectives are to: 1) use the six IOM-endorsed patient-centeredness dimensions as a framework to outline why patient-reported measures are crucial to the reliable measurement of patient-centered care; and 2) to identify existing patient-reported measures that assess each patient-centered care dimension.

Methods: For each IOM-endorsed patient-centeredness dimension, the published literature was searched to highlight the essential role of patients in assessing patient-centered care and informing quality improvement efforts. Existing literature was also searched to identify examples of patient-reported measures that assess each patient-centeredness dimension.

Conclusion: Patient-reported measures are arguably the best way to measure patient-centeredness. For instance, patients are best positioned to determine whether care aligns with patient values, preferences, and needs and the Measure of Patient Preferences is an example of a patient-reported measure that does so. Furthermore, only the patient knows whether they received the level of information desired, and if information was understood and can be recalled. Patient-reported measures that examine information provision include the Lung Information Needs Questionnaire and the EORTC QLQ-INFO25. In relation to physical comfort, only patients can report the severity of physical symptoms and whether medications provide adequate relief. Patient-reported measures that investigate physical comfort include the Pain Care Quality Survey and the Brief Pain Inventory. Using patient-reported measures to regularly measure patient-centered care is critical to identifying areas of health care where improvements are needed.

Keywords: patient-centered care, quality of care, quality assessment, patient-reported measures

\section{Measuring the quality of patient-centered care}

The Institute of Medicine (IOM) recommended that to achieve high quality health care, improvements were needed to the delivery of patient-centered care. ${ }^{1}$ Patientcentered care is responsive to patients' values and needs and patient preferences guide decision-making. ${ }^{1}$ The IOM endorsed six dimensions of patient-centered care which stated that care must be: 1) respectful to patients' values, preferences, and expressed needs; 2) coordinated and integrated; 3) provide information, communication, and education; 4) ensure physical comfort; 5) provide emotional support - relieving fear 
and anxiety; and 6) involve family and friends. ${ }^{1}$ The six dimensions of patient-centered care endorsed by the IOM ${ }^{1}$ were established by the Picker Institute. ${ }^{2}$ During the development of the six patient-centeredness dimensions, Gerteis et al drew on empirical research, theory, and patient and provider surveys to maximize validity. ${ }^{2}$ The Picker Institute ${ }^{3}$ and the International Association of Patients' Organizations (IAPO) ${ }^{4}$ have proposed alternative frameworks of patient-centered care. However, the principles in the Picker Institute' ${ }^{3}$ and IAPO' ${ }^{4}$ models of patient-centered care are similar to and largely overlap with the IOM-endorsed patient-centeredness dimensions.

Patient-reported measures developed to assess the quality of patient-centered care include measures of satisfaction with care and measures of experiences of care. ${ }^{5,6}$ Patient-reported measures are essential to quality improvement efforts as they provide the patient's perspective in relation to areas of health care that are of high quality and aspects of care where improvements are needed. ${ }^{7}$ Patient-reported measures are arguably the best way to assess constructs that relate to patient-centeredness given that patient-centered care is responsive to the patient and is guided by patient preferences. ${ }^{1}$ Patient-reported measures are also able to collect information that can only be obtained from patients themselves such as whether the patient received adequate pain relief. ${ }^{8}$

Given the IOM used the six patient-centeredness dimensions developed by Gerteis et $\mathrm{al}^{2}$ to recommend improvements to the delivery of patient-centered care, ${ }^{1}$ the IOM-endorsed patient-centeredness framework is used in this article. The objectives were: 1) to use the six IOM-endorsed dimensions of patient-centered care as a framework ${ }^{1}$ to highlight the crucial role of patient-reported measures in the accurate assessment of the quality of patient-centered care; and 2) to identify examples of existing patient-reported measures that measure each IOM-endorsed patient-centeredness dimension. To examine these objectives, the published literature was searched to obtain evidence in relation to the role of patients in the assessment of patient-centered care and the importance of patients' perspectives for informing quality improvement efforts. The published literature was also searched to identify examples of patient-reported measures that assessed each IOM-endorsed dimension of patient-centered care.

This article makes an important contribution to the literature by collectively examining all six IOM-endorsed patient-centeredness dimensions and discussing reasons why it is important to measure each dimension of patientcentered care. Examples of measures that assess the patient-centeredness dimensions are provided to encourage rigorous assessment of patient-centered care. Using a suite of measures to comprehensively and accurately assess from the patient's perspective all dimensions of patient-centered care could assist with prioritizing areas of patient-centeredness where improvements are most needed and facilitate quality improvement efforts.

\section{Respectful to patients' values, preferences, and expressed needs}

The IOM recommended that health care should be respectful of patients' cultural and other values, preferences, and needs. ${ }^{1}$ Patients should feel able to express views, be involved in decision-making according to their preferences, and receive respectful care. ${ }^{1}$ Patient-centered communication delivered by health care providers has been associated with better patient emotional health, ${ }^{9}$ and answering patient questions associated with better long-term patient psychosocial adjustment. ${ }^{10}$ Furthermore, patients with a good health care provider relationship indicated greater satisfaction with care and adherence to prescribed treatment. ${ }^{11}$

A mismatch between physicians' understanding of patients' preferences for treatment and decision-making has been found. ${ }^{11}$ However, patients themselves are most knowledgeable about whether care aligns with their values, preferences, and needs. The mismatch between physicians' perspectives and patients' views regarding the delivery of care highlights the need to regularly measure patients' preferences and experiences to ensure that care is responsive to patient values and needs. Examples of patient-reported measures that assess patient values, preferences, and needs include the Measure of Patient Preferences, that examines the manner physicians deliver care about cancer diagnosis and management ${ }^{12}$ and the modified version of the Perceived Involvement in Care Scale. ${ }^{13}$

\section{Coordinated and integrated care}

The IOM stated that health care should be coordinated and integrated and include timely transfer of up-to-date patient information to health care professionals, and efficient transition of patients between health care settings. ${ }^{1}$ A systematic review reported that effective interventions that improved the coordination of cancer care were those that provided follow-up, case management, and one-stop clinics. ${ }^{14}$ Research with newly diagnosed colorectal cancer patients indicated that problems with coordination of care were associated with poorer ratings of overall cancer care. ${ }^{15}$ Furthermore, a specialized respiratory coordinated care community program for people with advanced chronic 
obstructive pulmonary disease, demonstrated improvements to length of stay, readmission rates, and hospital admissions per patient per year. ${ }^{16}$

As health care increasingly occurs across various settings and involves several health care professionals, it may be difficult for these providers to determine whether overall patient care was coordinated and integrated. Therefore, patientreported measures could be used to capture patients' perspectives of the delivery of coordinated and integrated care and this information could supplement health care records in order to assess the quality of this aspect of care. Patientreported measures that assess the delivery of coordinated and integrated care include the Cancer Care Coordination Questionnaire for Patients, ${ }^{17}$ the Client Perceptions of Coordination Questionnaire, ${ }^{18}$ and the Care Coordination Measure for the Consumer Assessment of Healthcare Providers and Systems $\left(\right.$ CAHPS $\left.^{\circledR}\right)$ Medicare Survey. ${ }^{19}$

\section{Information, communication, and education}

The IOM recommended that patients receive clear, accurate, and understandable information about all aspects of care according to the patient's preference, including in relation to diagnosis, prognosis, treatments, follow-up, and support services. ${ }^{1}$ A systematic review of cancer patient informational needs indicated that $10 \%-24 \%$ of patients had unmet information needs at diagnosis and 11\%-97\% had unmet information needs during treatment. ${ }^{20}$ A survey of advanced cancer patients reported that they were least satisfied with information regarding prognosis and pain management. ${ }^{21}$ Diabetes patients have also reported dissatisfaction with information received at diagnosis $(20 \%)$, and wanted further information about the disease and medications $(24 \%){ }^{22}$

Only the patient knows whether they received the level of information desired, communication was appropriate, and if information was understood and recalled, highlighting the importance of using patient-reported measures to accurately assess the quality of information delivery in regards to patient care. Examples of patient-reported measures that assess information provision in relation to health care include the Lung Information Needs Questionnaire, developed with chronic obstructive pulmonary disease patients, ${ }^{23}$ and the EORTC QLQ-INFO25 a measure for cancer patients. ${ }^{24}$

\section{Physical comfort}

The IOM recommended that health care promptly provide appropriate pain relief to patients and attend to physical symptoms and needs. ${ }^{1}$ Cancer patients, particularly those with advanced disease, commonly experience fatigue $(60 \%-90 \%)^{25,26}$ and pain (64\%). ${ }^{27}$ Fatigue after stroke ranges between $38 \%$ and $77 \%,{ }^{28}$ and nociceptive pain is experienced by $5 \%-84 \%$ of stroke patients. ${ }^{29}$ Despite the availability of efficacious treatments, almost $50 \%$ of cancer patients with pain are under-treated, ${ }^{30}$ and $40 \%-73 \%$ reported receiving no assistance or treatment for cancer-related fatigue. ${ }^{26,31}$ Cancer patients who experience fatigue use health care services more frequently than those who do not experience fatigue. ${ }^{32}$ Additionally, more than two-thirds of stroke patients with longterm pain had no or inadequate prescribed pain treatment. ${ }^{29}$

Patient-reported measures are recognized as the gold standard for assessing cancer pain and fatigue. ${ }^{33}$ Only patients themselves can report the severity of fatigue, pain or physical symptoms, and whether medications provide adequate pain relief. This highlights the importance of using patient-reported measures to determine whether health care appropriately attends to patient comfort. Patient-reported measures that assess physical comfort include the Pain Care Quality Survey, ${ }^{34}$ the Brief Pain Inventory used for clinical pain assessment across cultures, ${ }^{35}$ and the Patient-Reported Outcomes Measurement Information System Pain Interference measure. ${ }^{36}$

\section{Emotional support - relieving fear and anxiety}

The IOM stated that health care should address patients' emotional and spiritual concerns, including anxiety due to uncertainty, fear, financial impact, or effect on family. ${ }^{1}$ Anxiety ranges from $10 \%-49 \%$ in cancer patients and depression from $0 \%-49 \%$ and are highest during cancer diagnosis and recurrence. ${ }^{37} \mathrm{~A}$ literature review indicated that $9 \%-26 \%$ of stroke survivors experience severe depression, $16 \%-52 \%$ acute depression, and $17 \%$ agoraphobia. ${ }^{38}$ Unmet need among cancer patients for psychological assistance ranges from $12 \%-85 \%$, with such unmet needs most common during treatment. ${ }^{20}$ Furthermore, almost one quarter $(23 \%)$ of people with diabetes wanted more reassurance and psychological support. ${ }^{22}$

Clinician accuracy of patient psychosocial well-being can be poor, as demonstrated by only $17 \%$ of cancer patients classified as clinically anxious and $6 \%$ as clinically depressed perceived as such by oncologists. ${ }^{39}$ Using patient-reported measures to assess the level of emotional support provided can inform quality improvement efforts by determining if health care services adequately address patients' emotional needs and reduce psychological distress. Widely used patientreported measures for assessing the emotional well-being of 
patients include the Hospital Anxiety and Depression Scale ${ }^{40}$ and Beck Depression Inventory. ${ }^{41}$

\section{Involvement of family and friends}

The IOM recommended that family and friends are involved in patient care and decision-making according to patient preferences and that care is responsive to the needs of family and friends. ${ }^{1}$ Family and friends can improve patient-provider rapport, facilitate information exchange, encourage decisionmaking involvement, and increase patient satisfaction. ${ }^{42}$ However, families and friends of stroke patients have reported feeling inadequately informed about and involved in patient care. ${ }^{43} \mathrm{~A}$ review found that major issues faced by cancer caregivers included managing their own and patient's psychological concerns, medical symptoms, side effects, and daily activities. ${ }^{44}$ Family members of cancer patients have been found to be more likely to have unmet needs about information in relation to supportive care than for medical information. $^{45}$

Only the patient can determine if family and friends were involved in care according to the patient's wishes. A systematic review of patient-reported measures examining patient-centered care among cancer patients reported that few patient-reported measures assess whether the involvement of family and friends in health care aligns with patient preferences. ${ }^{7}$ Family and friends are best able to accurately assess if their own concerns and needs were adequately addressed during the provision of health care. Measures that assess the needs and experiences of family and friends include the Support Person Unmet Needs Survey ${ }^{46}$ and the Quality of Family Experience measure, that assesses the experiences of families with a patient with a serious illness. ${ }^{47}$

\section{Conclusion}

Accurate measurement of the quality of patient-centered care is essential to informing quality improvement efforts. Using patient-reported measures to measure patient-centered care from patients' perspectives is critical to identifying and prioritizing areas of health care where improvements are needed. Patients are well positioned to provide reliable and valid information about the delivery of patient-centered care. For instance, only patients are able to accurately determine whether care was respectful to patients' values, preferences, and needs. Regularly using patient-reported measures to accurately assess the quality of patient-centered care could assist with promptly identifying areas of care where improvements are required and consequently may facilitate advancements to the delivery of patient-centered care.

\section{Acknowledgments}

This research was undertaken by the Priority Research Centre for Health Behaviour at the University of Newcastle which receives infrastructure support from the Hunter Medical Research Institute. Dr Flora Tzelepis was supported by a Leukaemia Foundation of Australia and Cure Cancer Australia Foundation Post-Doctoral Research Fellowship.

\section{Disclosure}

The authors declare that they have no conflict of interest.

\section{References}

1. Institute of Medicine. Crossing The Quality Chasm: A New Health System for the 21st Century. Washington DC: National Academy Press; 2001.

2. Gerteis M, Edgman-Levitan S, Daley J, Delbanco TL. Through the Patient's Eyes. Understanding and Promoting Patient-centered Care. San Francisco, CA: Jossey-Bass; 1993.

3. Australian Commission on Safety and Quality in Health Care. Patientcentred care: Improving quality and safety through partnerships with patients and consumers. Sydney: ACSQHC; 2011.

4. International Alliance of Patients' Organizations. Declaration on Patient-Centred Healthcare. London: IAPO; 2006.

5. Crow R, Gage H, Hampson S, et al. The measurement of satisfaction with healthcare: implications for practice from a systematic review of the literature. Health Technol Assess. 2002;6(32):1-244.

6. Cleary PD, Edgman-Levitan S. Health care quality. Incorporating consumer perspectives. JAMA. 1997;278(19):1608-1612.

7. Tzelepis F, Rose SK, Sanson-Fisher RW, Clinton-McHarg T, Carey ML, Paul CL. Are we missing the Institute of Medicine's mark? A systematic review of patient-reported outcome measures assessing quality of patient-centred cancer care. BMC Cancer. 2014;14:41.

8. Fink R. Pain assessment: the cornerstone to optimal pain management. Proc (Bayl Univ Med Cent). 2000;13(3):236-239.

9. Stewart M, Brown JB, Donner A, et al. The impact of patient-centered care on outcomes. J Fam Prac. 2000;49(9):796-804.

10. Butow PN, Dunn SM, Tattersall MH, Jones QJ. Computer-based interaction analysis of the cancer consultation. Br J Cancer. 1995;71(5): $1115-1121$

11. Ha JF, Longnecker N. Doctor-patient communication: A review. Ochsner J. 2010;10(1):38-43.

12. Parker PA, Baile WF, de Moor C, Lenzi R, Kudelka AP, Cohen L. Breaking bad news about cancer: patients' preferences for communication. J Clin Oncol. 2001;19(7):2049-2056.

13. Smith MY, Winkel G, Egert J, Diaz-Wionczek M, DuHamel KN. Patient-physician communication in the context of persistent pain: validation of a modified version of the patients' Perceived Involvement in Care Scale. J Pain Symptom Manage. 2006;32(1):71-81.

14. Ouwens M, Hulscher M, Hermens R, et al. Implementation of integrated care for patients with cancer: a systematic review of interventions and effects. Int J Qual Health Care. 2009;21(2):137-144.

15. Ayanian JZ, Zaslavsky AM, Guadagnoli E, et al. Patients' perceptions of quality of care for colorectal cancer by race, ethnicity, and language. J Clin Oncol. 2005;23(27):6576-6586.

16. Spiliopoulos N, Clark E, Donoghue J, Dunford M. Outcomes from a respiratory coordinated care program (RCCP) providing communitybased interventions for COPD patients from 1998 to 2006. Contemp Nurse. 2009;31(1):2-8.

17. Young JM, Walsh J, Butow PN, Solomon MJ, Shaw J. Measuring cancer care coordination: development and validation of a questionnaire for patients. BMC Cancer. 2011;11:298.

18. McGuiness C, Sibthorpe B. Development and initial validation of a measure of coordination of health care. Int J Qual Health Care. 2003; 15(4):309-318. 
19. Hays RD, Martino S, Brown JA, et al. Evaluation of a care coordination measure for the consumer assessment of healthcare providers and systems (CAHPS) Medicare survey. Med Care Res Rev. 2014;71(2): 192-202.

20. Harrison J, Young J, Price M, Butow P, Solomon M. What are the unmet supportive care needs of people with cancer? A systematic review. Support Care Cancer. 2009;17(8):1117-1128.

21. Hannon B, Swami N, Krzyzanowska MK, et al. Satisfaction with oncology care among patients with advanced cancer and their caregivers Qual Life Res. 2013:22(9):2341-2349.

22. Beeney LJ, Bakry AA, Dunn SM. Patient psychological and information needs when the diagnosis is diabetes. Patient Educ Couns. 1996; 29(1):109-116.

23. Hyland ME, Jones RC, Hanney KE. The Lung Information Needs Questionnaire: Development, preliminary validation and findings. Respir Med. 2006;100(10):1807-1816.

24. Arraras JI, Greimel E, Sezer O, et al. An international validation study of the EORTC QLQ-INFO25 questionnaire: an instrument to assess the information given to cancer patients. Eur J Cancer. 2010;46(15): 2726-2738.

25. Barnes E, Bruera E. Fatigue in patients with advanced cancer. Int $J$ Gynecol Cancer. 2002;12(5):424-428.

26. Curt GA, Breitbart W, Cella D, Groopman JE, Horning SJ, Itri LM, et al. Impact of cancer-related fatigue on the lives of patients: new findings from the Fatigue Coalition. Oncologist. 2000;5(5):353-340.

27. van den Beuken-van Everdingen MH, de Rijke JM, Kessels AG, Schouten HC, van Kleef M, Patijn J. Prevalence of pain in patients with cancer: a systematic review of the past 40 years. Ann Oncol. 2007; 18(9):1437-1449.

28. Lerdal A, Bakken L, Kouwenhoven S, et al. Poststroke fatigued: a review. J Pain Symptom Manage. 2009;38(6):928-949.

29. Widar M, Samuelsson L, Karlsson-Tivenius S, Ahlstrom G. Long-term pain conditions after stroke. J Rehabil Med. 2002;34(4):165-170.

30. Deandrea S, Montanari M, Moja L, Apolone G. Prevalence of undertreatment in cancer pain. A review of published literature. Ann Oncol. 2008;19(12):1985-1991.

31. Vogelzang NJ, Breitbart W, Cella D, et al. Patient, caregiver, and oncologist perceptions of cancer-related fatigue: Results of a tripart assessment survey. Semin Hematol. 1997;34(3 Suppl 2):4-12.

32. Ashbury FD, Findlay H, Reynolds B, McKerracher K. A Canadian survey of cancer patients' experiences: are their needs being met? J Pain Symptom Manage. 1998;16(5):298-306.
33. Von Roenn JH, Cleeland CS, Gonin R, Hatfield AK, Pandya KJ. Physician attitudes and practice in cancer pain management. A survey from the Eastern Cooperative Oncology Group. Ann Intern Med. 1993; 119(2):121-126.

34. Beck SL, Towsley GL, Pett MA, et al. Initial psychometric properties of the Pain Care Quality Survey (PainCQ). J Pain. 2010;11(12): 1311-1319.

35. Cleeland CS, Ryan KM. Pain assessment: global use of the Brief Pain Inventory. Ann Acad Med Singapore. 1994;23(2):129-138.

36. Amtmann D, Cook KF, Jensen MP, et al. Development of a PROMIS item bank to measure pain interference. Pain. 2010;150(1):173-182.

37. van't Spijker A, Trijsburg RW, Duivenvoorden HJ. Psychological sequelae of cancer diagnosis: a meta-analytical review of 58 studies after 1980. Psychosom Med. 1997;59(3):280-293.

38. Ferro JM, Caeiro L, Santos C. Poststroke emotional and behavior impairment: A narrative review. Cerebrovasc Dis. 2009;27 Suppl 1: 197-203.

39. Newell S, Sanson-Fisher RW, Girgis A, Bonaventura A. How well do medical oncologists' perceptions reflect their patients' reported physical and psychosocial problems?: Data from a survey of five oncologists. Cancer. 1998;83(8):1640-1651.

40. Zigmond AS, Snaith RP. The hospital anxiety and depression scale. Acta Psychiatr Scand. 1983;67(6):361-370.

41. Beck A, Ward C, Mendelson M, Mock J, Erbaugh J. An inventory for measuring depression. Arch Gen Psychiatry. 1961;4:561-571.

42. Hardin SR, Bernhardt-Tindal K, Hart A, Stepp A, Henson A. Criticalcare visitation: the patients' perspective. Dimens Crit Care Nurs. 2011; 30(1):53-61.

43. Hafsteinsdottir TB, Vergunst M, Lindeman E, Schuurmans M. Educational needs of patients with a stroke and their caregivers: a systematic review of the literature. Patient Educ Couns. 2011;85(1):14-25.

44. Kim Y, Carver CS. Recognizing the value and needs of the caregiver in oncology. Curr Opin Support Palliat Care. 2012;6(2):280-288.

45. Adams E, Boulton M, Watson E. The information needs of partners and family members of cancer patients: A systematic literature review. Patient Educ Couns. 2009;77(2):179-186.

46. Campbell HS, Sanson-Fisher R, Taylor-Brown J, Hayward L, Wang XS, Turner D. The cancer support person's unmet needs survey: psychometric properties. Cancer. 2009;115(14):3351-3359.

47. Steinhauser KE, Voils CI, Bosworth HB, Tulsky JA. Validation of a Measure of Family Experience of Patients with Serious Illness: The QUAL-E (Fam). J Pain Symptom Manage. 2014;48(6):1168-1181.
Patient Preference and Adherence

\section{Publish your work in this journal}

Patient Preference and Adherence is an international, peer-reviewed, open access journal that focuses on the growing importance of patient preference and adherence throughout the therapeutic continuum. Patient satisfaction, acceptability, quality of life, compliance, persistence and their role in developing new therapeutic modalities and compounds to optimize

\section{Dovepress}

clinical outcomes for existing disease states are major areas of interest for the journal. This journal has been accepted for indexing on PubMed Central. The manuscript management system is completely online and includes a very quick and fair peer-review system, which is all easy to use. Visit http://www. dovepress.com/testimonials.php to read real quotes from published authors. 